\title{
Modeling Cross Category Purchase Decision Making with Consumers' Mental Budgeting Control Habit
}

\author{
Zhiguo Yang \\ Information Technology and Cybersecurity Department, \\ College of Business, Missouri State University, USA \\ yzg1236@hotmail.com
}

\begin{abstract}
Cross-category decision making is an ongoing research in decision science. Cross-category modeling is a powerful tool for big data and business analytics. Cross-category decision making involves evaluating multiple categories for complementary/substitutional utilities. This paper examines consumers' mental budgeting control habit for its impact on cross purchase decisions. This factor has not been examined in existing cross modeling literature. This paper fits a base cross category model and a budgeting control habit cross model using a consumer grocery shopping dataset. The results show that by incorporating this variable in the cross model, model fit score and prediction accuracy are significantly improved. The budgeting control habit factor has significant moderating effects on price effects and cross price effects. In addition to providing the modeling technique, this paper also finds that consumers classify basket items into root and add-on categories. The common sense that price drop boosts sales is only true for the root category items. Price drop of add-on items may trigger consumers reconfiguring their basket items but not necessarily increase sales of the add-on items themselves.
\end{abstract}

Keywords: Cross-category decision, cross-category modeling, consumer behavior, mental budgeting.

\section{Introduction}

Cross purchase modeling (cross model) is a method to simultaneously analyze multiple product categories for their interrelated influences on consumers' decisions to purchase each category (Yang and Sudharshan 2019). For example, Cake Mix and Frosting are often purchased together, would a discount on Cake Mix, impact sales of Frosting and how? Cross category models are important tools in business administration such as forecasting demand for grocery stores (Manchanda et al., 1999, Duvvuri et al., 2007), understanding and predicting multiple financial products choices (Li et al., 2005), and utilizing spatial distance and assortment layout of multiple categories for better shopping experience (Leeflang and Parreño-Selva, 2012, Hong et al., 2016). Extant cross models have made considerable progress in modelling heterogeneity across individuals in cross-category purchase effects. However, they do not model the impact of variations in individual budgets from shopping occasion to shopping occasion. Such variations are likely to occur as suggested by Mental budgeting/accounting theory (Thaler, 1985, Heath and Soll, 1996) which suggests that consumers explicitly or implicitly put a mental effort in maintaining a spending budget and justify unplanned expenditure by relabeling money from one category to another (Stilley et al., 2010). As Vohs and Faber (2007) elaborated, some consumers exhibit greater budget control than others. To extend the cross-category modeling method, this paper studies the impact of incorporating budget control habit factor $(\mathbf{B C H})$ in a cross model.

In other words, faced with stimuli such as promotions or changes in price some consumers are better at controlling how much and what they spend on versus others. This variation across customers, we suggest, should play a role in cross-category purchases. Customers may label a group of products to be jointly needed to justify buying them while others may label them as not being related purchases. Those who exhibit tighter control may be more inclined to or adept at decoupling products while those who have less control may have more difficulty in decoupling products and thus may buy them even when they are not promoted or when budgets are tight. We argue that this ability to exhibit budget control is likely to be a consumer characteristic and be an influencer in consumer decision making in cross-category purchase. The BCH factor is expected to have a moderating effect in cross category purchase decision making. Suppose we look at the cross purchase between Cake Mix and Frosting. When Cake Mix price drops, we assume consumers buy more Cake Mix and at the same time buy more Frosting because these two are used together to make cake. But this assumption is not always valid if we consider consumers' mental budgeting control habit. For consumers of mild or low budgeting control, buying more of both can be justified by the consumption complementarity. 
But for consumers of strong budgeting control, buying more of both is not a good choice because of the concern of over-spending. Not addressing this factor in cross model can result in convoluted outcomes because the variation of $\mathrm{BCH}$ among consumers leads to variation of purchase decisions. Habits are the result of one's personal history of behavior. Thus habits are unique and idiosyncratic (Danner et al., 2011). This paper quantifies $\mathrm{BCH}$ in a scale. The left end is the frugal, the consumers engaging little mental budgeting control in shopping; the right end is prodigal, the ones being used to intensive mental budgeting control. Most consumers should have a score in between the frugal and prodigal. This $\mathrm{BCH}$ score reflects a common character of consumers. We all have met people who count every penny in shopping and try to avoid overspending by any means, and other people who are easily get attracted by promotions, make impulsive purchases and have very little concern for overspending.

Impulsive buying literature is also highly relevant in studying consumers' mental budgeting control habit. Impulsive buying is a kind of behavior that consumers make unplanned purchases. Majority of the literature are devoted to examining the external and internal stimuli such as emotions (Weinberg and Gottwald, 1982) and social norms (Rook and Fisher, 1995). Mental budgeting control habit is a personal trait that guides how much mind power a consumer usually uses in matching the spending and budget. Apparently, level of mental budgeting control should negatively relate to frequency of impulsive buying. Consumers of low mental budgeting control can appear strong in impulsive buying intension because the 2 factors both reflect less concern for overspending. Many other factors are relevant to mental budgeting control habit such as the durable vs. non-durable goods. This study focuses on grocery shopping and leaves the durable goods factor to future studies. Figure 1 shows a theoretical construct of mental budgeting control habit in cross category purchase model. We argue that the mental budgeting control habit have a moderating effect in cross category purchase decision making.

\section{Figure 1: Moderating Effect of Mental Budgeting Control Habit in Cross Model}

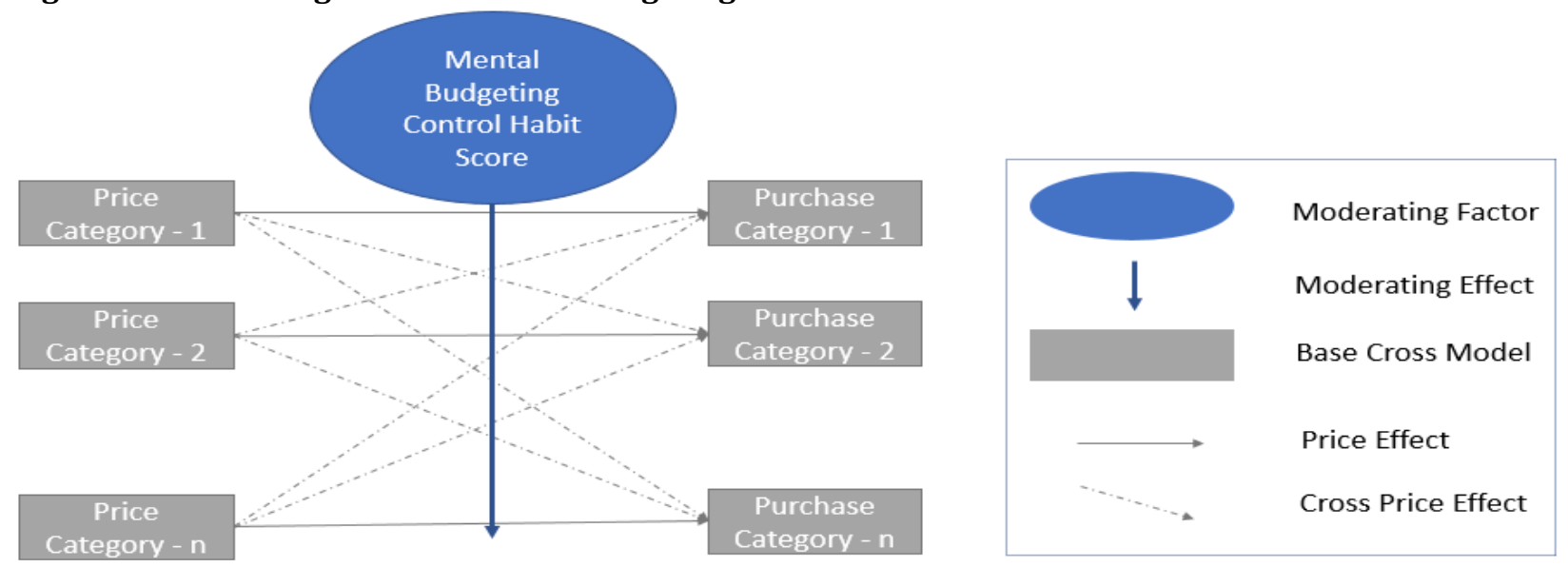

The base model is a typical cross category model that estimates price effects and cross price effects. The moderating effect model is derived from the base model by adding the control habit moderator to price and cross effects. It is easy to justify the moderator construct over alternative constructs. As discussed earlier, stronger mental budgeting control can imply less cross purchases because cross purchases usually lead to over spending. A moderating effect emerges from the fact that the price and cross price effects are dependent on consumers mental budgeting control habit. This study has several contributions to multiple category purchase research. First, we extend the cross category modeling technique by incorporating mental budgeting control habit factor. It helps managers better understand consumers' cross purchase behavior. Since the cross purchase models are capable in analyzing complex data structure, this research contributes to big data and business analytics methodology. The results of this paper show that by incorporating the $\mathrm{BCH}$ factor in a cross model we can significantly improve model fit and prediction accuracy, and the cross-model results can be more reasonably explained. As a by-product of this research, we discuss the basket root items phenomenon. We find that combining the control habit factor and basket root items perspective can better explain the dynamics of consumers' decision making in cross category purchase. 


\section{Literature Review}

Thaler (1985) is the seminal paper of mental accounting research. Behavioral economists suggest investigating factors above and beyond the economic rationality and utility. For example, for same amount of money, people tend to value the hardly earned cash more than the easy money from lottery or casino wins. Heath and Soll (1996) articulate that consumers label expendable money into categories such as entertainment fund or household expense. They also track expenditures against the money labels. Thaler (1999) generalizes the mental accounting activities as labeling activities, evaluation of outcomes, and frequency of evaluations. Consumers spend different amount of time on each of these activities to meet their decision-making needs. The current study is an effort to examine the evaluation and frequency of evaluations. The evaluations of budget control outcome have a strong impact on consumers' decision making. As shown in Langer and Weber (2001), manipulating the form of participants' evaluations in a lottery purchase can lead to significant change of consumers' purchasing behavior. In addition to the evaluation form, we argue that the intensity of evaluation is another important factor that can influence consumers' decision making. Some consumers may have a habit to use less mind power to evaluate their mental budgeting control. This type of consumer does not concern for over spending and are often to mentally search for ways to justify their floppy budgeting control. Cheema and Soman (2006) find that consumers can re-label an expense from one to another spending category in order to justify an over-spending. We believe that consumers have different habits in mental budgeting control.

In the current study, we try to capture this variable by each individual consumer's spending history data. Stilley et al. (2010) also provides evidence for varying mental budgeting control habit among consumers. They found that consumers set flexible money in groceries shopping. And we believe that the balance of flexible money account is very different in consumers. This variable can guide part of consumers' decision in spending. Mental budgeting is related to personality traits such as self-control (Kivetz and Simonson, 2002) (Krishnamurthy and Prokopec, 2009). As to future research opportunities, we call for research in consumer's spending structure reconfiguration behavior. In both online and offline shopping, consumers are used to buy multiple items in one shopping trip. Understanding why and how consumers reconfigure their spending structure can have huge impacts on marketing management. The current study contends that consumers are heterogeneous in the level of engagement in mental budgeting control and the level of engagement is a stable personality trait that has an influence on purchase decision making in each shopping trip the consumer made. Because the habit is a stable personality character, it can be captured as a general variable. The current paper is also inspired by Homburg et al. (2010), which studied the moderating effect of mental budgeting on the relationship between price and future purchase decisions. The current study takes it further and argues that (1) consumers have formed a mental budgeting control habit for shopping and (2) the habit score has a significant power in multi-category cross purchases modeling. Mental budgeting control habit is highly relevant to impulsive buying behavior.

Impulsive buying is a behavior of making unplanned purchase. This behavior can be attributed to internal factors such as a result shopper's emotion (Weinberg and Gottwald, 1982) and psychological mechanism (Strack and Deutsch, 2006). The choices of product categories and specific time period should be carefully examined. The set of categories should come from same spending label such as grocery, appliance or entertainment. As mental budgeting theory suggested, consumers label funds and expenditure into categories (Heath and Soll, 1996). Thus, it is very possibly that consumers' spending is relatively consistent at the labeled category level. External factors are also examined such as social norms (Rook and Fisher, 1995) and culture (Kacen and Lee, 2002). In addition to these known factors, we argue that consumers have a personality trait that sets a base tone for consumer's responsiveness to stimuli of impulsive buying. Prodigal consumers are supposed to be more subject to impulsive buying because they are less concerned for overspending. Studies are accumulating in examining personal traits for impulsive buying behavior. We argue that consumers budgeting control habit is most possibly consistent when purchase the same product categories. The choice of specific time period should be long enough to ensure a general trait being extracted; but at same time not too long to mess up habit changes. Strack and Deutsch (2006) investigate psychological mechanism of impulsive buying. Vohs and Faber (2007) study the influence of self-regulatory resource availability in impulsive buying behavior. Figure 2 shows the two schools of literature where derives the mental budgeting control habit construct. 
Figure 2: Mental Budgeting Control Habit Construct and Literature Extension

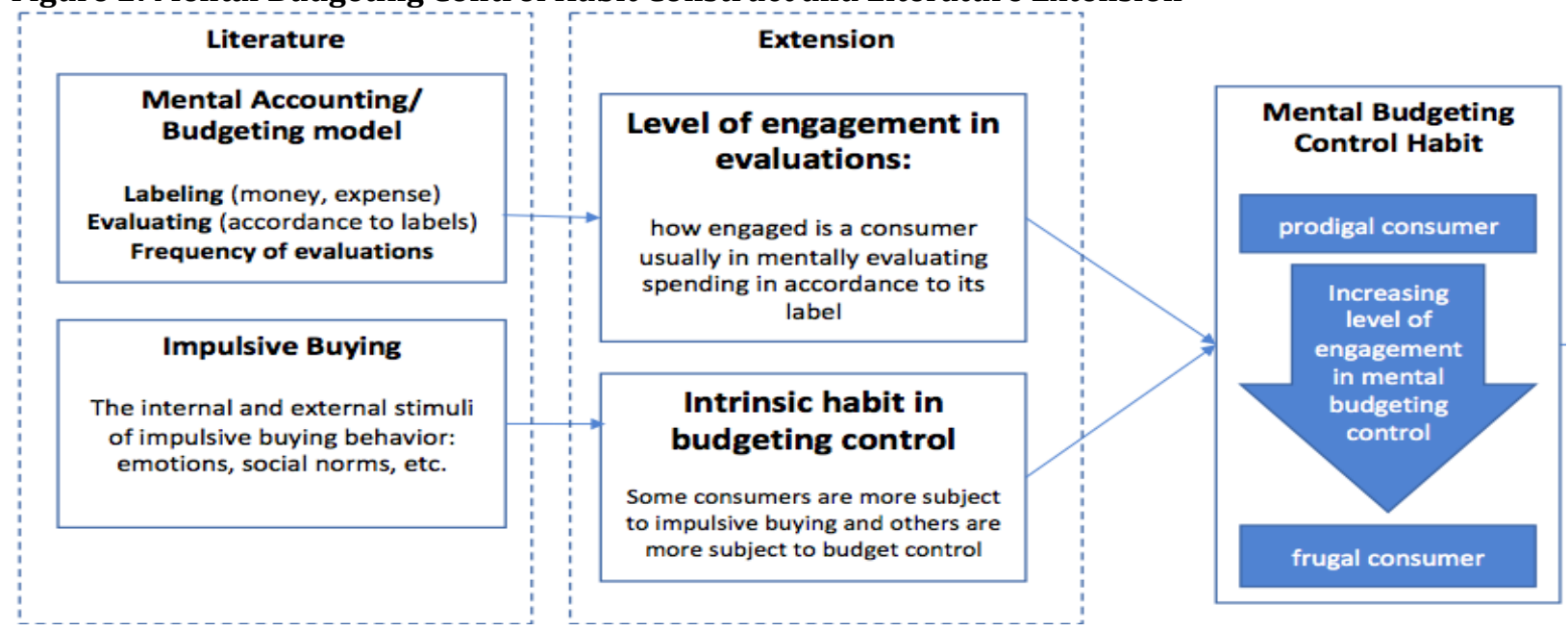

\section{Method}

This section first establishes the mental budgeting control variable, and then proposes two comparable models that can be used to show the impact of this factor on improving model fit and prediction performance in cross purchases context. The two models, base cross model and budgeting control habit model, are derived from multivariate probit (MVP) model (Manchanda et al., 1999)( Duvvuri et al., 2007). The former model does not include the mental budgeting control factor and the latter model includes it as a moderating factor.

Budgeting Control Habit (BCH) Variable: Habits are the result of one's personal history of behavior (Danner et al., 2011). A habit can be captured by data of personal behavioral history. Budgeting control habit thus is embedded in shopping history data. The BCH Score is calculated as the standard deviation of a consumer's spending on a related set of product categories over a specific time period. The current study uses grocery spending category and 2 years of shopping history data to calculate the budgeting control habit score. Figure 3 shows the histogram of extracted score variable.

Figure 3: Mental Budgeting Control Habit Score Histogram

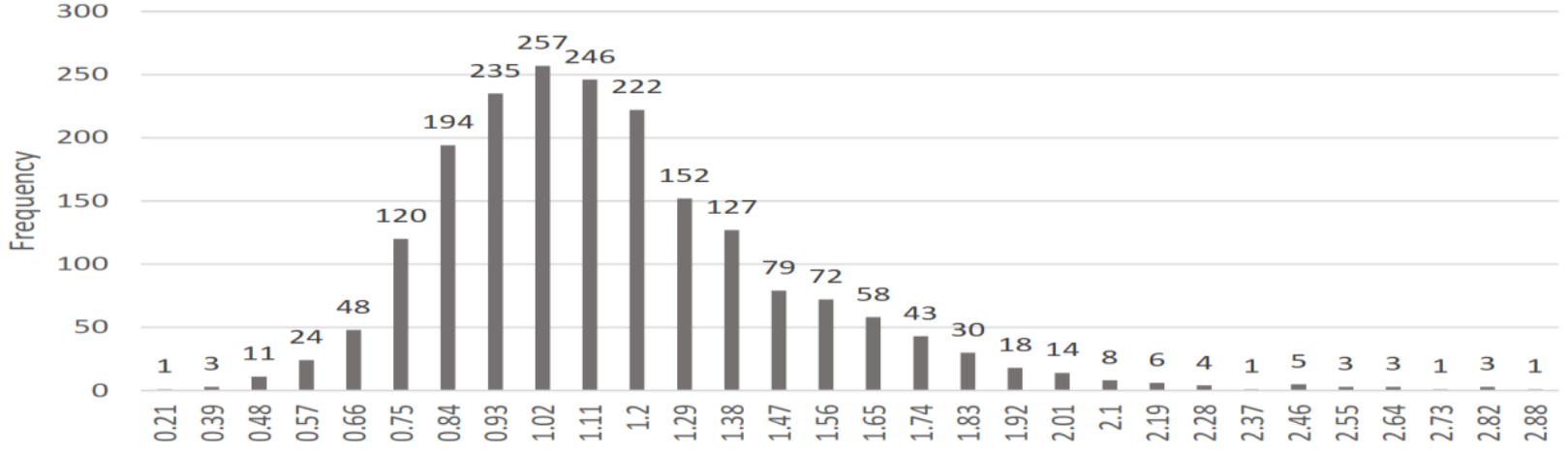

MVP and Latent Utility Model: The MVP model is derived from and the latent utility model or random utility model (McFadden 1973; 1980; 1986) (Walker and Ben-akiva 2002). Here we briefly explain latent utility model. In a shopping trip $t$, consumer $h$ 's purchase choice over $k$ categories can be expressed by a vector $y_{t h}=\left\{y_{1}, y_{2}, \ldots, y_{k}\right\}_{t h}$. The element $y_{\mathrm{k}}$ is a binary variable and $y_{\mathrm{k}}=1$ indicates that the category $k$ is purchased (or not purchased for $y_{\mathrm{k}}=0$ ). The value of $y_{\mathrm{kth}}$ is modeled with a latent utility variable (not observed) $u_{k t h}$ as:

$$
y_{k t h}= \begin{cases}0 \text { (not purchase }), & u_{k t h} \leq 0 \\ 1 \text { (purchase }), & u_{k t h}>0\end{cases}
$$


The latent utilities vector is further regressed on dependent variables as:

$$
\begin{array}{r}
\boldsymbol{u}_{t h}=X_{t h} \boldsymbol{\beta}_{h}+\boldsymbol{\varepsilon}_{t h} \\
\boldsymbol{\varepsilon}_{t h} \sim \operatorname{MVN}(\mathbf{0}, \Sigma)
\end{array}
$$

Dependent variable (DV) $\boldsymbol{u}_{t h}$ is a $k$-dimesion vector for $k$ categories, $\boldsymbol{u}_{t h}=\left\{u_{1 t h}, u_{2 t h}, \ldots u_{k t h}\right\}$. The $X_{t h}$ is the matrix of independent variable. The matrix $\boldsymbol{\beta}$ are the effect parameters. Since $\boldsymbol{u}$ is inferred from the observed variable $\boldsymbol{y}$, the model allows all positive value of $\boldsymbol{u}$ when corresponding category is purchased $(y=1)$, and allows all negative values when not purchased $(y=0)$. Given an observation $(X, y)$, the parameters $\left(\boldsymbol{\beta}_{h}, \Sigma\right)$ cannot be uniquely identified because $\boldsymbol{u}$ is free to change in the range $(0,+\operatorname{Inf})$ or $(-\operatorname{Inf}, 0)$. To solve this problem, this study follows the practice of existing literature and restricts the error covariance matrix, $\Sigma$, to a correlation matrix (Manchanda et al., 1999, Rossi et al., 2005, Duvvuri et al., 2007).

Base Cross Model: Our base cross model uses the MVP model shown above. We include price and cross price in the independent variables. The key part of the model is:

$$
\boldsymbol{u}_{t h}=\text { price }_{t h} \boldsymbol{\beta}_{h}+\varepsilon_{t h}
$$

The $\boldsymbol{p r i c e}_{t h}$ is a $k * k$ matrix. Each row contains the $\mathrm{k}$ categories prices and there are k rows corresponding to $\boldsymbol{u}_{t h}$ vector. The $\boldsymbol{\beta}_{h}$ is a k*k matrix containing own price effect and cross price effect for the $\mathrm{k}$ categories. The detailed specification in a matrix form is:

$$
\left[\begin{array}{c}
u_{1 t h} \\
u_{2 t h} \\
\ldots \\
u_{k t h}
\end{array}\right]=\left[\begin{array}{c}
\text { price }_{1 t h} * \boldsymbol{\beta}_{11 h}, \text { price }_{2 t h} * \beta_{12 h}, \ldots, \text { price }_{k t h} * \beta_{1 k h} \\
\text { price }_{1 t h} * \beta_{21 h}, \text { price }_{2 t h} * \boldsymbol{\beta}_{22 h}, \ldots, \text { price }_{k t h} * \beta_{2 k h} \\
\ldots \\
\text { price }_{1 t h} * \beta_{k 1 h}, \text { price }_{2 t h} * \beta_{k 2 h}, \ldots, \text { price }_{k t h} * \boldsymbol{\beta}_{\boldsymbol{k k h}}
\end{array}\right]+\left[\begin{array}{c}
\varepsilon_{1 t h} \\
\varepsilon_{2 t h} \\
\ldots \\
\varepsilon_{k t h}
\end{array}\right]
$$

The bolded betas, $\boldsymbol{\beta}_{\mathbf{1 1} \boldsymbol{h}} \sim \boldsymbol{\beta}_{\boldsymbol{k} \boldsymbol{k} \boldsymbol{h}}$, are own price effects and other betas are cross effects.

It is well known that the relation between price and utility is negative. That translates into expected negative beta values for $\boldsymbol{\beta}_{\mathbf{1 1 h}} \sim \boldsymbol{\beta}_{\boldsymbol{k} \boldsymbol{k} \boldsymbol{h}}$. Unlike own price effect, cross price effect does not have an obvious direction. Some people assume positive correlations of demands between complementary goods such as Cake Mix and Frosting, the mental budgeting factor makes consumers' actual behavior unpredictable. For weakly complementary goods categories such as Bacon and Eggs, it is even harder to make solid assumptions about their correction direction. The direction of cross effects can depend on many factors. But the mental budgeting control habit is expected to have general moderating effect on price and cross price effect.

Budgeting Control Habit Model: We create the mental budgeting control habit model by adding moderating terms to the base cross model. The key part of the model is:

$$
\boldsymbol{u}_{t h}=\text { price }_{t h} \boldsymbol{\beta}_{h}+\text { price }_{t h} \text { ControlHabitScore }_{h} \boldsymbol{\beta}_{h}{ }_{h}+\varepsilon_{t h}
$$

The $2^{\text {nd }}$ term of right hand side of the equation is the moderating term of the mental budgeting control habit factor. The coefficient vector, $\boldsymbol{\beta}^{\prime}{ }_{h}$, will capture the moderating effect of the control habit variable on the price and cross price effect (refer to Baron and Kenny (1986) for moderating effect). Significant $\boldsymbol{\beta}^{\prime}{ }_{h}$ indicate significant moderating effects. By comparing the model fit score and prediction accuracy between the base model and the budgeting control habit model, we can validate the importance of including the mental budgeting control habit factor in cross models. For the moderating effect direction, we expect that budgeting control habit score will enhance price and cross price effect. Specifically, the price and cross price effect will be strengthened at the frugal consumer side (low control habit); but the cross price effect will be weakened at the prodigal consumer side (high control habit).

\section{Results}

Model Estimation: Gibbs sampling method is used to estimate the base and budgeting control habit model (Rossi et al., 2005, page 63). The likelihood calculation from the Gibbs output is not straight forward. We use Chib (1995) method and calculate the log-likelihood score for the 2 models. The models are implemented by customizing an open source R package bayesm (Rossi, 2012). $\mathrm{R}$ is an open source data analysis tool (R Core 
Team 2014). The program customization is based on the rmvpGibbs function in the bayesm package and refers to the book Rossi et al. (2005) and the work of Allenby et al. (2005) and Duvvuri et al. (2007).

Data: This study uses a dataset extracted from the Nielsen Consumer Panel and Scanner database and focuses on archival data of year 2010 and 11 US cities. Information of availability and access to the dataset is available at http://research.chicagobooth.edu/nielsen. We include 4 categories Cake mix, Frosting, Detergent and Softener. These categories are commonly used in cross effect research (Manchanda et al., 1999, Duvvuri et al., 2007). We first retain the households who made at least 2 purchases in any of the 4 categories in year 2010. To reduce the difficulty of model estimation caused by large dataset, we further retain only the households for 11 cities as shown in the following table. We try to make the cities geographically spread across US (by DMA code) to minimize the location bias. Trips and purchases are then extracted corresponding to these households. The final dataset information is shown in Table 1. The dataset is split into $85 \%$ and $15 \%$ for model fitting and testing. Table 2 shows purchases and joint purchases statistics.

\section{Table 1: Dataset Information}

\section{Period: \\ Year 2010}

Cities (by DMA Area code)

New York, Chicago, St Louis, Dallas, Los Angeles, Boston, Houston,

San Francisco, Seattle, Atlanta, Minneapolis

Trip Information

Categories

Valid Trips

Valid Households

Trips/Household

Cake mix, Frosting, Detergent,

Softener

21,606

1,705

12.67

Table 2: Purchases and Joint Purchases

\begin{tabular}{lllll}
\hline & Cake Mix & Frosting & Detergent & Softener \\
\hline Cake mix & 2451 & 963 & 176 & 56 \\
Frosting & & 1685 & 118 & 45 \\
Detergent & & 3147 & 337 \\
Softener & & & & 1109 \\
\hline
\end{tabular}

*The counts of single category purchases include the joint purchases.

Model Fit and Prediction Hit Rate: Prediction hit rate and model fit likelihood scores are shown in Table 3. The log likelihood score is $-142,951.4$ for the control habit model and $-145,023.2$ for the base cross model. The higher likelihood score indicates that the control habit model has a better data-model fit. The control habit model achieved 0.821 prediction hit rate comparing with 0.819 hit rate of the base model. The results provide strong evidence for the non-ignorable influence of budgeting control habit factor in multi-category cross purchase.

Table 3: Prediction and Log-Likelihood of Base and Mental Budgeting Control Habit Model

\begin{tabular}{|c|c|c|}
\hline & Prediction Hit Rate & Log-Likelihood Score \\
\hline Base Cross Model & 0.819 & $-145,023.2$ \\
\hline $\begin{array}{l}\text { Budgeting Control Habit Cross } \\
\text { Model }\end{array}$ & 0.821 & $-142,951.4$ \\
\hline
\end{tabular}

The estimated model parameters are shown in Table 4. The parameters of base model are shown in the lower section shaded. The control habit model parameters are shown in the above section non-shaded. 
Table 4: Spending Habit Cross Model and Base Cross Model parameters

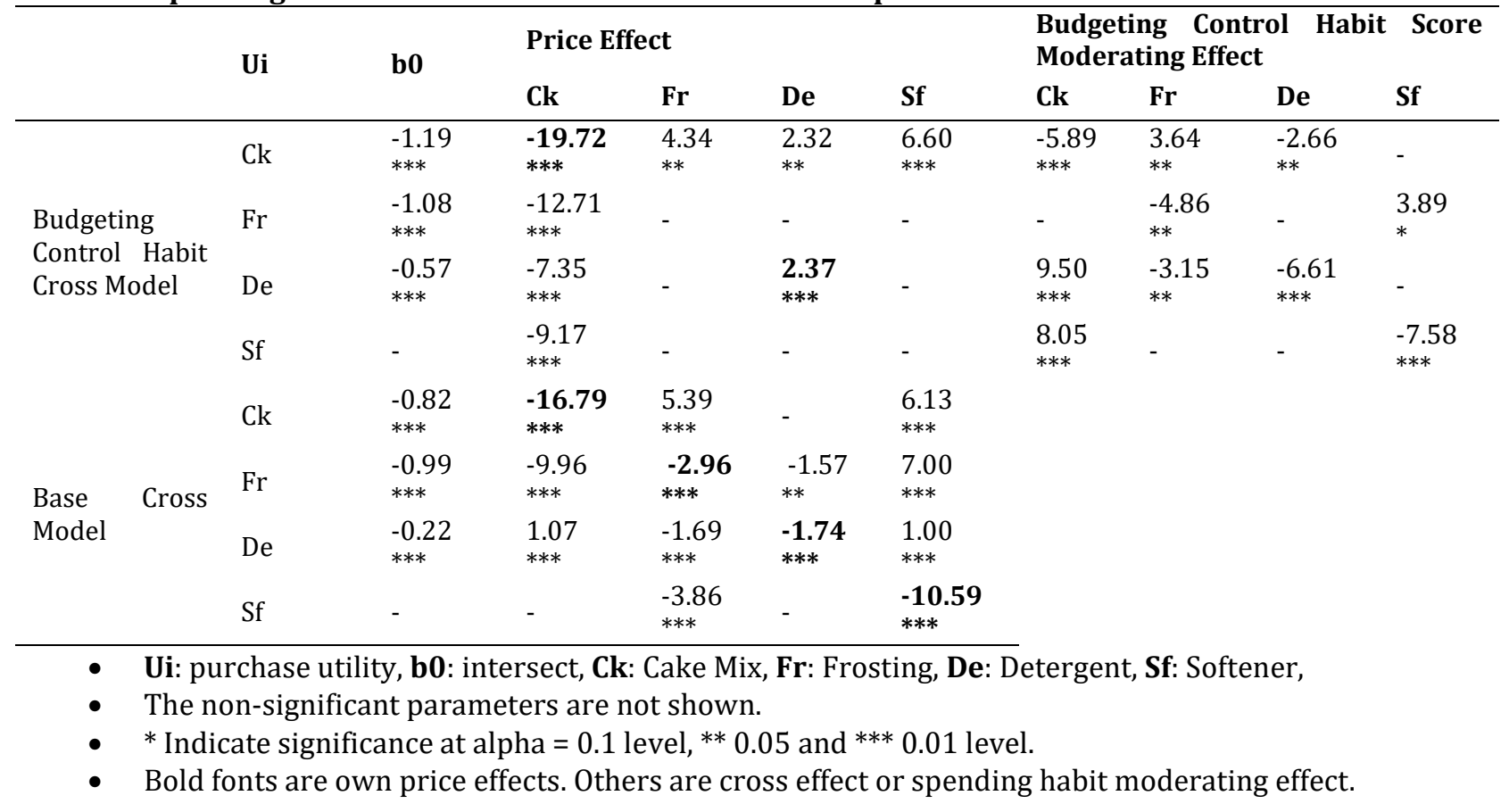

The base model own price effects are in bold fonts in the shaded section. A face validity of the model fit is achieved because the own price effects are all negative. It is a common principle that price drop is associated with increase utility of purchases. In the following discussions, we will focus on understanding the cross effects.

Base Cross Model Parameters: Cake Mix Price Effect column has 3 significant effects as -16.79 on itself, 9.96 on Frosting and 1.07 on Detergent. It suggests that Cake Mix price drop can lead to purchase of (1) more Cake Mix, (2) more frosting and (3) less Detergent. The effect size rank is Cake Mix strongest, frosting medium and Detergent weak. The Frosting price drop has influence on all the 4 categories. But the effects on Cake Mix and Softener are stronger than on frosting itself. But frosting effect on Cake Mix is positive, which means a price drop of Frosting can indicate less Cake Mix purchase. This can be explained by the spending habit factor and consumers spending structure reconfiguration behavior (See Discussion section). It is also important to compare the effects horizontally. Cake Mix's utility is dominated by its own price, -16.79 . The price of Frosting and Softener also has impacts as 5.39 and 6.13. The positive scores indicate that price drop leads to less purchase. But these effects are 3 times less influential than the Cake Mix's own price effect. For Frosting, all cross price effects are significant. But the effects from Cake Mix, -9.96, and Softener, 7.00, are much stronger than Frosting's own effect, -2.96. This is surprising because consumers are much more responsive to cross price effects than to own price effect. Also, against intuition is that Softener price drop leads to less purchase of Frosting. Again, we will provide our explanation in the discussion section.

BCH Cross Model Parameters: We first compare the Budgeting Control Habit model estimation with the base model estimation. First observation is that Frosting and Softener's own price effect become insignificant in the $\mathrm{BCH}$ model. Instead, the $\mathrm{BCH}$ moderating effects are significant on these price effects. At price drop of these categories, consumers' purchase decision depends on consumers' budgeting control habit score. If the control habit score is bigger than 1, then the price drop effect is enhanced and vice versa. In an extreme case that control habit score is close to 0 , price effect will become very light and close to none. Cake Mix and Detergent's own price effects remain significant and the BCH moderating effects are significant as well. Consumers are responsive to price drop independently and $\mathrm{BCH}$ score will enhance or weaken the responsiveness respectively. For Cake Mix, the own price effect and moderating effect are -19.72 and -5.89 . Consumers' response to price drop is mainly determined by its own price and the influence from $\mathrm{BCH}$ factor is relatively small. For Detergent, the own price effect and moderating effect are 2.37 and -6.61 . Consumers' 
response to price varies and highly depends on $\mathrm{BCH}$ score. Solving the equation $2.37 *$ price $+(-6.61 *$ price $* B C H)=0$ results in $B C H \approx 0.36$. This is the point where the price effect and moderating effect cancel out each other. Consumers with $\mathrm{BCH}$ score 0.36 are unpredictable for their response to price drop consumer with $\mathrm{BCH}$ score bigger than 0.36 are possible to purchase more at price drop and consumers with $\mathrm{BCH}$ less than 0.36 are possible to purchase less.

Spending Reconfiguration Behavior: We contend that consumers mentally reconfigure their basket items to achieve many goals including mental budgeting control and consumption utility maximization. Considering budgeting control habit in cross effect research, frugal consumers may have high priority of mental budgeting control over the utility of products complementary consumption; while prodigal consumers may have opposite priority. The different priority leads to consumers adjusting purchase categories and quantity. The linkage from consumers' budgeting control habit to different behaviors of basket item reconfiguration is one example of investigating spending reconfiguration behavior. We call for more research in investigating spending reconfiguration behavior. It is very common that consumers purchase multiple items in one shopping trip, online or in store. Understanding why, when and how consumers reconfigure basket items can help marketers better serve consumers.

\section{Discussion}

This paper is the first study examining consumer's mental budgeting control habit factor in cross models. Comparing with earlier studies, this paper provides a novel method of incorporating consumers' budget control factor.

Budgeting Control Habit Moderating Effects: The results of some cross effects could be confusing if not explained in the budgeting control habit structure. For example, the base model Frosting column shows significant price effects as 5.39 on Cake Mix, -2.96 on Frosting, itself -1.69 on Detergents and -3.86 on Softeners. The positive effect on Cake Mix indicates that a price drop of Frosting lead to less Cake Mix purchase. If we look at it from the product complementary/substitution perspective, it is hard to understand this fact. Let us consider consumers' mental budgeting control habit. Assume that a consumer usually only buy cake mix, say 10 units. Seeing a price drop of Frosting, they decide to buy Frosting, as well. But Cake Mix and Frosting have an optimal amount ration to be consumed together, say $[10,10]$. This situation forces the consumer to buy 10 Frosting to match usual Cake Mix purchase. Unfortunately, it will highly possibly lead to an overspending. As a result, the consumer purchases $[5,5]$ to avoid over spending but also maintain an optimal combination.

In this scenario, Frosting price drop leads to purchase pattern from $[10,0]$ to $[5,5]$, an increase in Frosting purchase and decrease in Cake Mix. This speculated decision making pattern is very possible for frugal consumers who are habitually engaged in high mental budgeting control at shopping. The influence of moderating effects becomes even more obvious in the budgeting control model, which explicitly includes the BCH score. The model estimation shows that Frosting's own price effect is dependent on BCH factor. The combining effect from price and control habit is -4.68 . Since the BCH score value is always positive (See section 3.4), the combination effect thus is negative. But its effect size totally depends on the BCH score. Frugal consumers (BCH score at 0 side) will not response to price drop at all for Frosting, but prodigal consumers (BCH score at 3 side) will response to price drop 3 times stronger than will average consumers (BCH score at 1).

Root Basket Items: The $\mathrm{BCH}$ model parameter results clearly show that Cake Mix and Detergent are root categories in consumer basket because their independent own price effects are significant. Frosting and Softener are add-on categories that their independent own price effects disappear when the $\mathrm{BCH}$ moderator is added to the model. Importantly for add-on categories, consumers' responsiveness to price drop totally depend on the consumers' $\mathrm{BCH}$ score. This is strong evidence that consumers divide basket items into root categories and add-on categories. Combining the discussions in 6.1 and 6.2, we must conclude that the common sense of price drop boost purchase is only true for the root category items. Price drop of add-on items may trigger consumer's reconfiguration of their basket items but not necessarily lead to more purchases. 


\section{Conclusion and Recommendations}

Consumers' mental budgeting control habit is quantified using spending history. This paper shows strong evidence that the BCH score can reflect the habit in the frugal-prodigal scale. Store managers can utilize consumer's purchase history data to calculate the BCH score for each consumer, and then apply this score in consumer classifications, which is the fundamental technique of many marketing applications such as email promotion and personalization. The proposed $\mathrm{BCH}$ cross category model can better forecast demands. Because cross models incorporate multiple categories simultaneously in forecasting, it provides a more accurate forecasting than single category models. Both physical and online stores should utilize the BCH cross model in demand forecasting. Managers also can utilize the model to find out the root vs. add-on items in cross purchase context. As discussed in 5.3, promotions are more effective when used on root basket items than on add-on items. Identifying root basket items in cross purchase context can help reduce promotion cost by focusing on the more effective promotions. This paper also shows that consumers engage in basket items reconfiguration to meet budgeting goal. Managers, especially online store managers, can offer suggestions for optimal configuration according to consumers' BCH score. Frugal side consumers prefer savings and monetary values; while prodigal side consumers tend to like more the symbolic, informatics and novelty values. These finds can be applied in recommender system research and applications, which have been a popular topic in e-commerce development.

\section{References}

Allenby, G. M., Rossi, P. E. \& McCulloch, R. E. (2005). Hierarchical Bayes Models: A Practitioners Guide. SSRN working paper, Ohio State University, University of Chicago.

Cheema, A. \& Soman, D. (2006). Malleable mental accounting: The effect of flexibility on the justification of attractive spending and consumption decisions. Journal of Consumer Psychology, 16(1), 33-44.

Chib, S. (1995). Marginal likelihood from the Gibbs output. Journal of the American Statistical Association, 90(432), 1313-1321.

Danner, U. N., Aarts, H., Papies, E. K. \& de Vries, N. K. (2011). Paving the path for habit change: Cognitive shielding of intentions against habit intrusion. British journal of health psychology, 16(1), 189-200.

Duvvuri, S. D., Ansari, A. \& Gupta, S. (2007). Consumers' price sensitivities across complementary categories. Management Science, 53(12), 1933-1945.

Heath, C. \& Soll, J. B. (1996). Mental budgeting and consumer decisions. Journal of Consumer Research, 23(1), 40-52.

Homburg, C., Koschate, N. \& Totzek, D. (2010). How price increases affect future purchases: the role of mental budgeting, income, and framing. Psychology \& Marketing, 27(1), 36-53.

Hong, S., Misra, K. \& Vilcassim, N. J. (2016). The perils of category management: the effect of product assortment on multi-category purchase incidence. Journal of Marketing, 80(5), 34-52.

Kacen, J. J. \& Lee, J. A. (2002). The influence of culture on consumer impulsive buying behavior. Journal of Consumer Psychology, 12(2), 163-176.

Kivetz, R. \& Simonson, I. (2002). Self-control for the righteous: Toward a theory of precommitment to indulgence. Journal of Consumer Research, 29(2), 199-217.

Krishnamurthy, P. \& Prokopec, S. (2009). Resisting that triple-chocolate cake: Mental budgets and self-control. Journal of Consumer Research, 37(1), 68-79.

Lally, P., Van Jaarsveld, C. H., Potts, H. W. \& Wardle, J. (2010). How are habits formed: Modelling habit formation in the real world. European journal of social psychology, 40(6), 998-1009.

Langer, T. \& Weber, M. (2001). Prospect theory, mental accounting, and differences in aggregated and segregated evaluation of lottery portfolios. Management Science, 47(5), 716-733.

Leeflang, P. S. \& Parreño-Selva, J. (2012). Cross-category demand effects of price promotions. Journal of the Academy of Marketing Science, 40(4), 572-586.

Manchanda, P., Ansari, A. \& Gupta, S. (1999). The "shopping basket": A model for multi-category purchase incidence decisions. Marketing Science, 18(2), 95-114.

McFadden, D. (1973). Conditional Logit Analysis of Qualitative Choice Behavior, in Frontier of Econometrics, ed. by P. Zarembka. New York: Academic Press.

McFadden, D. (1980). Econometric models of probabilistic choice in Structural Analysis of Discrete Data, ed. by C. Manski and D. McFadden. Cambridge, Mass.: M.I.T. Press. 
McFadden, D. (1986). The choice theory approach to market research. Marketing Science, 5(4), 275-297.

Core Team, R. (2014). R: A language and environment for statistical computing. R Foundation for Statistical Computing, Vienna, Austria.

Rook, D. W. \& Fisher, R. J. (1995). Normative influences on impulsive buying behavior. Journal of Consumer Research, 22(3), 305-313.

Rossi, P. E., Allenby, G. M. \& McCulloch, R. (2005). Bayesian Statistics and Marketing. John Wiley \& Sons.

Rossi, P., E. (2012). Bayesm: Bayesian Inference for Marketing/Micro-econometrics. R package version, 2, 2-5.

Stilley, K., M., Jeffrey, I., J. \& Kirk, W., L. (2010). Planning to make unplanned purchases? The role of in-store slack in budget deviation. Journal of Consumer Research, 37(2), 264-278.

Strack, F. \& Deutsch, R. (2006). Reflective and impulsive determinants of consumer behavior. Journal of Consumer Psychology, 16(3), 205-216.

Thaler, R. (1985). Mental accounting and consumer choice. Marketing Science, 4(3), 199-214.

Thaler, R. H. (1999). Mental accounting matters. Journal of Behavioral Decision Making, 12(3), 183.

Vohs, K. D. \& Faber, R. J. (2007). Spent resources: Self-regulatory resource availability affects impulse buying. Journal of Consumer Research, 33(4), 537-547.

Walker, J. \& Ben-Akiva, M. (2002). Generalized random utility model. Mathematical Social Sciences, 43(3), 303-343.

Weinberg, P. \& Gottwald, W. (1982). Impulsive consumer buying as a result of emotions. Journal of Business Research, 10(1), 43-57.

Yang, Z. \& Sudharshan, D. (2019). Examining multi-category cross purchases models with increasing dataset scale-An artificial neural network approach. Expert Systems with Applications, 120, 310-318. 